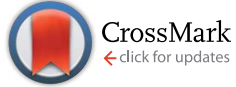

Cite this: RSC Adv., 2017, 7, 3907

Received 8th November 2016 Accepted 19th December 2016

DOI: $10.1039 / c 6 r a 26489 a$

www.rsc.org/advances

\title{
Achieving rough sphere-shaped ZnS with superior attenuation electromagnetic absorption performance
}

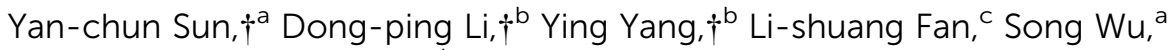 \\ Peng Wang*a and Yi Song*d
}

\begin{abstract}
ZnS micrometer spheres were prepared via a facile hydrothermal route. Polyvinyl pyrrolidone (PVP) was used as the surfactant. By controlling the PVP content, the smooth surface of ZnS sphere was converted to a rough surface, which led to a stronger electromagnetic wave scattering intensity when used as an electromagnetic absorption absorber. ZnS microspheres with the roughest surface showed the best electromagnetic absorption property. The absorption frequency of this product at $2.0 \mathrm{~mm}$ was $4.2 \mathrm{GHz}$. The minimum reflection loss was nearly $-35.0 \mathrm{~dB}$, indicating excellent attenuation ability. The attenuation mechanism is discussed in detail and was attributed to the scattering effect.
\end{abstract}

\section{Introduction}

Recently, the application of an electromagnetic absorber to treat the increasing electromagnetic wave interference (EMI) has attracted considerable attention., ${ }^{1,2}$ This functional material can make the electromagnetic wave incident on the absorption layer and convert it to thermal energy, depending on its intrinsic attenuation ability. ${ }^{3}$ To achieve a good electromagnetic absorption performance, better impedance matching behavior is the key to ensure less reflection of electromagnetic wave from the interface of the absorption layer. The incoming electromagnetic wave can then be attenuated because of the intrinsic physic loss features. Currently, metal oxides have are the desired absorbers owing to the impedance matching and attenuation ability. ${ }^{4,5}$ Currently, representative metal oxides, such as $\mathrm{Fe}_{3} \mathrm{O}_{4},{ }^{6} \mathrm{CoFe}_{2} \mathrm{O}_{4},{ }^{7} \mathrm{NiO},{ }^{8}$ and $\mathrm{CuO},{ }^{9}$ have been widely applied in electromagnetic absorption studies. For example, the optimal reflection loss of CoO nanoparticles prepared by Li et al. was estimated to be $-37.0 \mathrm{~dB} .{ }^{10}$ The minimum reflection loss $\left(\mathrm{RL}_{\min }\right)$ for the $\mathrm{Co}_{x} \mathrm{Fe}_{3-x} \mathrm{O}_{4}$ was up to $-41.089 \mathrm{~dB}$ at a thickness of $2.0 \mathrm{~mm}$, according to the Ji's report. ${ }^{11}$ The binary $\mathrm{NiCo}_{2} \mathrm{O}_{4} /$

${ }^{a}$ Heilongjiang River Fisheries Research Institute of Chinese Academy of Fishery Sciences, Laboratory of Quality \& Safety Risk Assessment for Aquatic Products (Harbin), Ministry of Agriculture, Harbin 150070, P. R. China. E-mail: Wapg911@ 126.com; Tel: +86-0451-84861321

${ }^{b}$ College of Chemical and Environmental Engineering, Harbin University of Science \& Technology, Harbin 150080, P. R. China

${ }^{c}$ Academy of Fundamental and Interdisciplinary Sciences, Harbin Institute of Technology, Harbin 150080, P. R. China

${ }^{d}$ Chinese Academy of Fishery Sciences, Beijing 100141, P. R. China. E-mail: songyi@ cafs.ac.cn; Fax: +86-0451-84604803

$\dagger$ These authors contributed equally to this work.
$\mathrm{CoNiO}_{2}$ sample also showed a $\mathrm{RL}_{\text {min }}$ value less than $-40 \mathrm{~dB}$ with a thickness of $1.5 \mathrm{~mm} .{ }^{12}$ Compared to metal oxides, recent research has shown that metal sulfides presented better dielectric loss ability if used in the electromagnetic absorber field. ${ }^{12,13}$ The primary reason is the improved conductive ability. ${ }^{14}$ According to the electromagnetic absorption mechanism, the improved conductive ability can lead to an increase in permittivity. In this case, the dielectric loss ability of metal sulfides is prominently stronger than those of the corresponding metal oxides notwithstanding a slight decrease in impedance matching performance..$^{15}$ For example, Lv and co-workers developed the $\mathrm{Fe}_{0.5} \mathrm{Ni}_{0.5} \mathrm{Co}_{2} \mathrm{~S}_{4}$ composite and obtained a $\mathrm{RL}_{\text {min }}$ value of $-14.0 \mathrm{~dB}$ with a thin coating thickness of $1.5 \mathrm{~mm}$. At the same time, the frequency region of $\mathrm{RL}<-10 \mathrm{~dB}$ was nearly $6.2 \mathrm{GHz} .{ }^{16}$ Through a simple top-down exfoliation method, few-layer $\mathrm{MoS}_{2}$ was achieved, the $\mathrm{RL}_{\text {min }}$ value was approximately $-38.42 \mathrm{~dB}$ and the frequency bandwidth was $4.1 \mathrm{GHz}$ with a thickness of $2.4 \mathrm{~mm} \cdot{ }^{17} \mathrm{In}$ addition, the $\mathrm{Fe}_{3} \mathrm{~S}_{4}$ introduced by Liu et al. had a minimum reflection loss of $-36.03 \mathrm{~dB}$ with a thickness of $3.0 \mathrm{~mm} .{ }^{18}$

Owing to the advantages of easy production and low-cost, considerable efforts have been focused on the ZnS absorber. ${ }^{19}$ In addition to these merits, $\mathrm{ZnS}$ also presents moderate conductive behavior and results in impedance matching and dielectric loss ability. Therefore, the development of $\mathrm{ZnS}$ is considered to be another efficient strategy to gain the desired electromagnetic absorber. In this study, sphere-like ZnS was obtained using a simple hydrothermal strategy. By controlling the contents of the surfactant, the $\mathrm{ZnS}$ surface was becoming increasingly rough. The electromagnetic absorption properties of these ZnS spheres were studied. 


\section{Experiment}

\subsection{Synthesis of ZnS sphere}

Sphere-like ZnS was prepared via a facile hydrothermal process. Typically, $0.1 \mathrm{~g}$ zinc acetate $\left(\mathrm{Zn}(\mathrm{Ac})_{2}\right)$ and $0.5 \mathrm{~g}$ thiourea (TA) were dispersed in $60 \mathrm{~mL}$ of distilled water (DI) for $30 \mathrm{~min}$ ultrasonic treatment to form a clear solution. A certain amount of pyrrolidone polyvinyl (PVP) was dispersed into the abovementioned solution to serve as the surfactant. After another 10 min of ultrasonic treatment, the abovementioned solution was transferred to a $100 \mathrm{~mL}$ autoclave and heated at $150{ }^{\circ} \mathrm{C}$ for 12 hours. After natural cooling, the precipitate was collected via centrifugation and washed several times with ethanol and distilled water. Finally, sphere-like ZnS was achieved after drying the precipitate at $60{ }^{\circ} \mathrm{C}$ for one day. The $\mathrm{ZnS}$ spheres obtained with the addition of $0,10,20$, and $30 \mathrm{mg}$ of PVP are denoted as ZS-1, ZS-2, ZS-3 and ZS-4, respectively.

\subsection{Measurement}

$\mathrm{X}$-ray diffraction (XRD, Rigaku Desktop X-ray diffractometer, $\mathrm{Cu}$ $\mathrm{K} \alpha$ radiation) was employed to test the crystalline phase of the ZnS samples: (test region: $20-70^{\circ}$, wavenumber $\lambda=0.15418 \mathrm{~nm}$; scanning voltage $=40 \mathrm{keV}$ ). The morphology of the samples was observed via Field Emission Scanning Electron Microscopy (FE-SEM, JEOL JSM-7100F) and equipped with Electron Energy Disperse Spectroscopy (EDS). The X-ray photoelectron spectrum was obtained on a PHI 5000 VersaProbe systems, in which an Al $\mathrm{K} \alpha \mathrm{X}$-ray source was operated at $150 \mathrm{~W}$. At the same time, a TEM image was obtained on a Tecnai G220 S-Twin. The complex permittivity and permeability parameters were measured on an Agilent 8722ES network analyzer. The cylindrical sample (inner diameter of $3.04 \mathrm{~mm}$ and outer diameter of $7.0 \mathrm{~mm}$ ) was fabricated by uniformly mixing a paraffin matrix with $60 \mathrm{wt} \%$ absorbents, and the composite was then pressed into a cylindrical mold. Transmission line theory was used to calculate the reflection loss.

\section{Results and discussion}

The morphology of ZnS sample (ZS-1) was characterized by FE-SEM. A sphere-structure can be observed in Fig. 1a. These ZnS spheres without adding PVP presented a smooth surface (in Fig. 2b). According to Fig. 1c, this $\mathrm{ZnS}$ sphere has a solid structure. Through EDS, only $\mathrm{Zn}$ and S signals were detected and the corresponding atomic ratio of $\mathrm{Zn} / \mathrm{S}$ was 52.1 to 48.9, which is approximately $50: 50$ (seen Fig. 1e). Fig. 1f also showed that the diameters of these $\mathrm{ZnS}$ spheres were primarily distributed in the range 5-7 $\mu \mathrm{m}$. In addition, a small part of the ZnS spheres was smaller than $1.0 \mu \mathrm{m}$, indicating that the size of these ZnS sphere is not uniform. Fig. If presents the XRD pattern of the sample. These diffraction peaks were matched to the standard XRD card (JCPDS card no: 75-1534) without other impurity peaks. X-ray photoelectron spectroscopy (XPS) revealed the binding energy values of $\mathrm{Zn}$ at 1022 and $1045 \mathrm{eV}$, which were attributed to $2 \mathrm{p}_{3 / 2}$ and $2 \mathrm{p}_{1 / 2}$ of $\mathrm{Zn}^{2+}$. At the same time, the binding energy of S $2 \mathrm{p}$ was $162 \mathrm{eV}$, corresponding to $\mathrm{S}^{2-} .^{20}$
In this study, the initial content of PVP plays a key role in the final structure. Fig. 3a-c show the $\mathrm{ZnS}$ obtained with a mass of 10, 20 and $30 \mathrm{mg}$. Through the FE-SEM images, the ZnS with varying content of PVP still showed a spherical structure. However, the surface of the ZnS spheres became more rugged with increasing PVP content.

The electromagnetic absorption properties of these $\mathrm{ZnS}$ samples were tested using a coaxial-line method. The electromagnetic parameters, including real/imaginary part of permittivity $\left(\varepsilon^{\prime} / \varepsilon^{\prime \prime}\right)$ as well as the permeability $\left(\mu^{\prime} / \mu^{\prime \prime}\right)$ were also obtained. The reflection loss at $2-18 \mathrm{GHz}$ was calculated using the following equations: ${ }^{21,22}$

$$
\begin{gathered}
Z_{\text {in }}=Z_{\mathrm{o}}\left(\mu_{\mathrm{r}} / \varepsilon_{\mathrm{r}}\right)^{1 / 2} \tanh \left[\mathrm{j}\left(2 \pi f d\left(\mu_{\mathrm{r}} \varepsilon_{\mathrm{r}}\right)^{1 / 2} / c\right)\right] \\
\mathrm{RL}(\mathrm{dB})=20 \log \left|\left(Z_{\mathrm{in}}-Z_{\mathrm{o}}\right) /\left(Z_{\text {in }}+Z_{\mathrm{o}}\right)\right| \\
\mu_{\mathrm{r}}=\mu^{\prime}-\mathrm{j} \mu^{\prime \prime} \\
\varepsilon_{\mathrm{r}}=\varepsilon^{\prime}-\mathrm{j} \varepsilon^{\prime \prime}
\end{gathered}
$$

where $Z_{\text {in }}$ is the input impedance of the absorber; $Z_{\mathrm{o}}$ accounts for the characteristic impedance of free space $(377 \Omega) ; f$ is the frequency of electromagnetic wave; $d$ is the coating thickness of the absorber; $c$ is the velocity of the light and $\mu_{\mathrm{r}}$ and $\varepsilon_{\mathrm{r}}$ are the complex permeability and permittivity values. For a desired electromagnetic absorber, the minimum reflection loss should be less than $-10 \mathrm{~dB}$ (corresponding to $90 \%$ of absorption and attenuation). The frequency region of $\mathrm{RL}<-10 \mathrm{~dB}$ is better when it is as broad as possible (denoted as the qualified frequency region). The reflection loss $v s$. frequency curves are given in Fig. 4. The qualified frequency bandwidth of ZS-1 was approximately $2.0 \mathrm{GHz}(14-16 \mathrm{GHz})$ with a coating thickness of $2.0 \mathrm{~mm}$. At other thicknesses $(d=2.5$ or $3.0 \mathrm{~mm})$, the qualified frequency bandwidth was smaller than $2.0 \mathrm{GHz}$ and the corresponding minimum reflection loss was larger than $-15.0 \mathrm{~dB}$. For ZS-2, however, the qualified frequency bandwidth was narrow and not more than $1.0 \mathrm{GHz}$ at $2.0 \mathrm{~mm}$, indicating a poor microwave absorption ability. For other thicknesses, the reflection loss of ZS-2 was even larger than $-10 \mathrm{~dB}$, as shown in Fig. 4b. In Fig. 4c, the qualified frequency bandwidth for ZS-3 was estimated to be $3.8 \mathrm{GHz}(14.2-18 \mathrm{GHz})$ at $2.0 \mathrm{~mm}$. In addition, the optimal reflection loss increased in the range from -15 to $-20 \mathrm{~dB}$. Further enhancement was observed for the ZS-4 sample, in which the frequency bandwidth at $2.0 \mathrm{~mm}$ was larger than $4.0 \mathrm{GHz}(13.8-18 \mathrm{GHz})$. The electromagnetic absorption properties of $\mathrm{ZS}-4$ are better than those of the similar products, as listed in Table $1 .{ }^{23-28}$ Most importantly, the $\mathrm{RL}_{\text {min }}$ value at $2.5 \mathrm{~mm}$ was below $-35 \mathrm{~dB}$, which was highest of these samples. Therefore, it can be concluded that ZS-4 achieved the strongest electromagnetic absorption ability while that of ZS-2 was poor.

To analyze the electromagnetic attenuation mechanism, the real and imaginary parts of permittivity are listed in Fig. 5a and $b$ (for the nonmagnetic material, the real part of permeability was a constant value of 1.0 and the imaginary part of the permeability value was almost 0$).{ }^{29}$ Based on the 

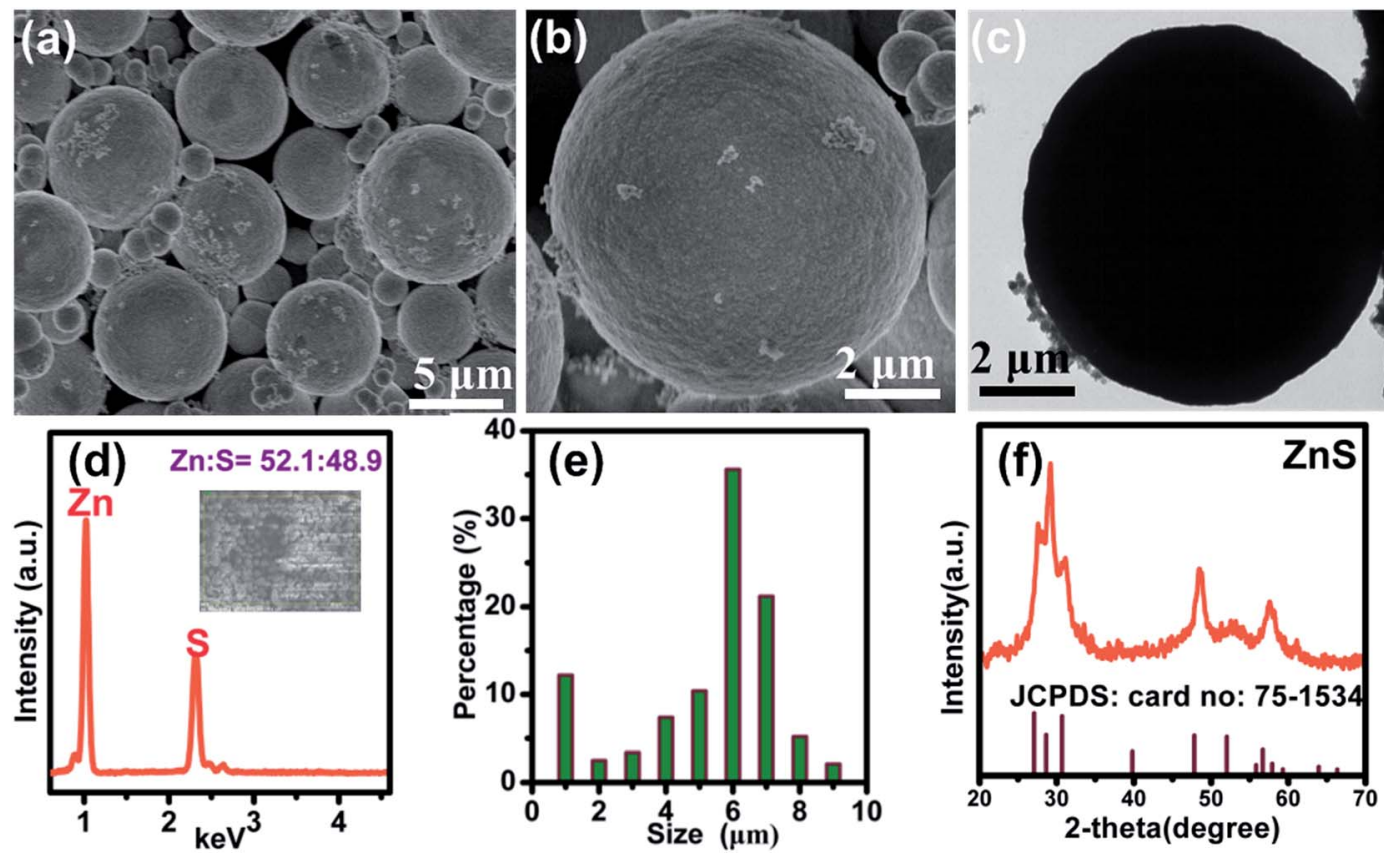

Fig. 1 ( $a$ and b) FE-SEM images (c) the TEM image of the ZnS prepared without PVP; (d) EDS spectrum (e) and size distribution of these ZnS micrometer spheres without the addition of PVP. (f) XRD patterns of the ZnS without PVP.
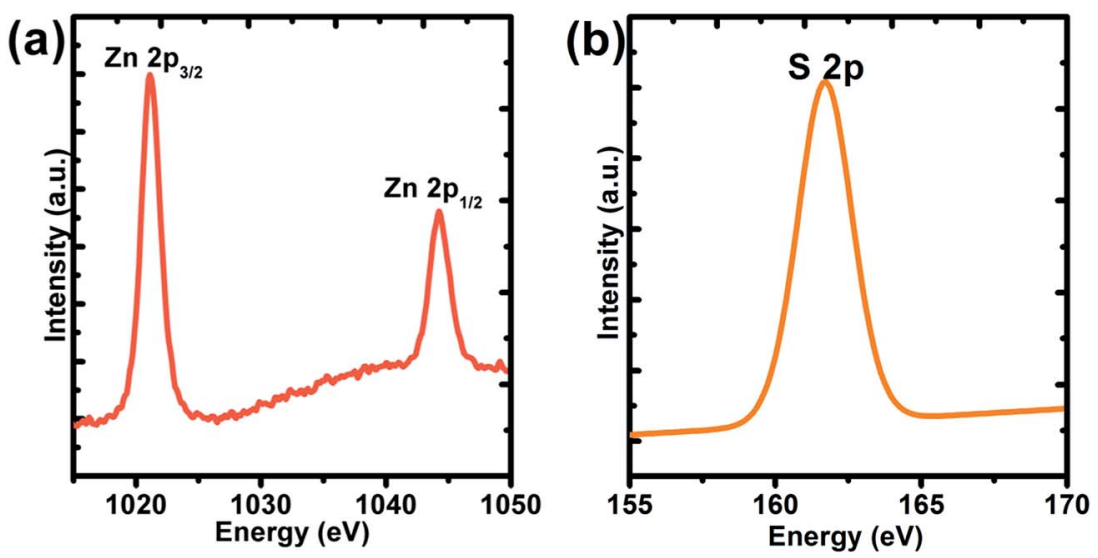

Fig. 2 XPS spectrum of the ZnS spheres prepared without the addition of PVP. (a) Zn 2p; (b) S 2p.
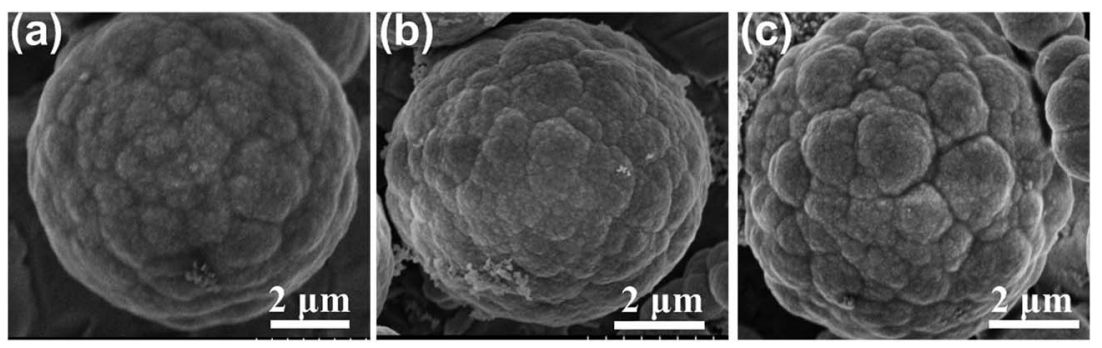

Fig. 3 FE-SEM images of the ZnS spheres with various amounts of PVP: (a) $10 \mathrm{mg}$; (b) $20 \mathrm{mg}$; (c) $30 \mathrm{mg}$.

electromagnetic absorption mechanism, the role of impedance matching and attenuation (including the dielectric and magnetic loss ability) is to determine the final electromagnetic absorption ability. In Fig. 4 a, these $\varepsilon^{\prime}$ values follow the order ZS$1<$ ZS-2 $<$ ZS-3 $<$ ZS-4. Generally, a larger $\varepsilon^{\prime}$ value indicates the better storage electrical ability but damages to the impedance 
(a)
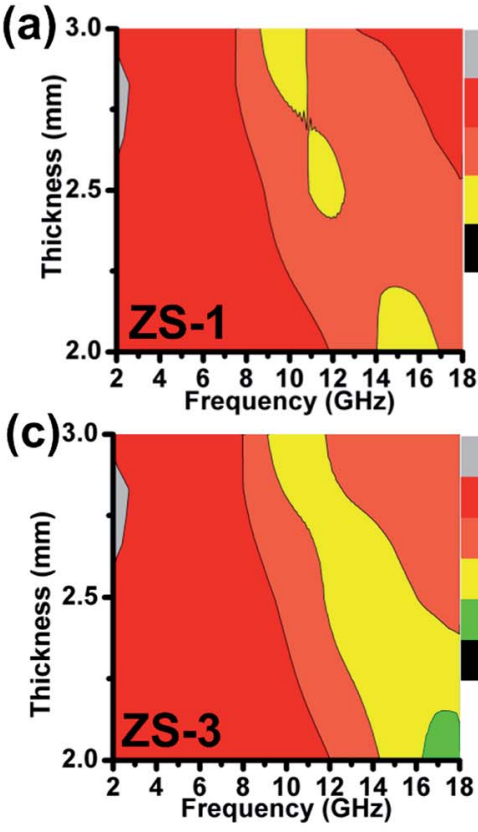

(b)

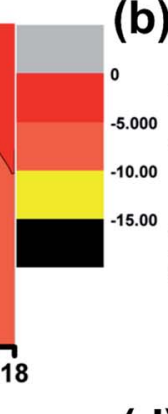

(d)

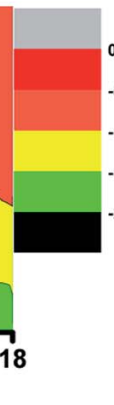

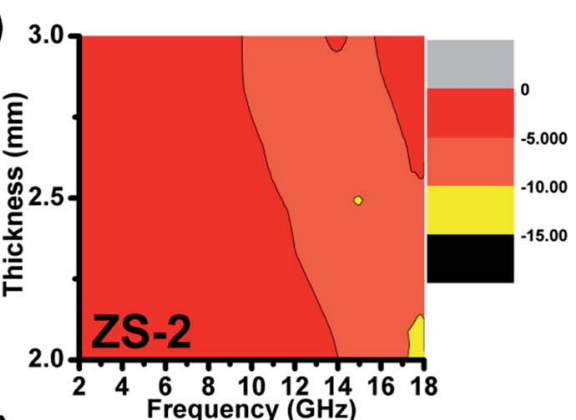

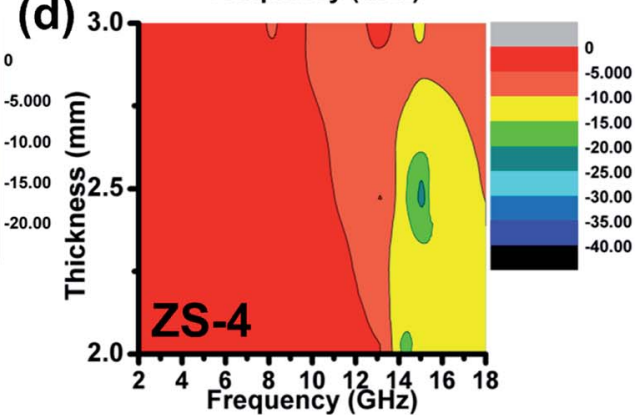

Fig. 4 Electromagnetic absorption spectrum of the ZnS samples: (a) ZS-1; (b) ZS-2; (c) ZS-3; (d) ZS-4.

Table 1 Electromagnetic absorption properties of similar metal sulfides

\begin{tabular}{llllll}
\hline Sample & $\begin{array}{l}f_{\mathrm{E}} \\
(\mathrm{GHz})\end{array}$ & $\begin{array}{l}\mathrm{RL}_{\text {min }} \\
(\mathrm{dB})\end{array}$ & $\begin{array}{l}\text { Filled ratio } \\
(\mathrm{wt} \%)\end{array}$ & $\begin{array}{l}\text { Thickness } \\
(\mathrm{mm})\end{array}$ & Ref. \\
\hline $\mathrm{ZnS}$ & $<2.0$ & -11.02 & 70 & 2.5 & 23 \\
$\mathrm{CuS}$ & $\sim 3.0$ & -25.0 & 10 & 2.0 & 24 \\
$\mathrm{CoS}$ & 0.0 & $<-10.0$ & 40 & 2.0 & 25 \\
$\mathrm{MoS}_{2}$ & 0.0 & $<-10.0$ & 10 & 2.0 & 26 \\
$\mathrm{MnS}$ & 0.0 & $<-10.0$ & 40 & 3.0 & 27 \\
$\mathrm{CuS} / \mathrm{ZnS}$ & $0 \mathrm{GHz}$ & $<-10 \mathrm{~dB}$ & N.A & 2.0 & 28 \\
$\mathrm{ZnS}$ & $4.2 \mathrm{GHz}$ & $-18 \mathrm{~dB}$ & 60 & 2.0 & In this work
\end{tabular}

matching performance. ${ }^{30}$ The $\varepsilon^{\prime \prime}$ value refers to the dielectric loss ability. For these nonmagnetic $\mathrm{ZnS}$ samples, the attenuation ability resulted was only from the dielectric loss. As shown in Fig. 5b, ZS-4 showed the largest $\varepsilon^{\prime \prime}$ value (1.8-2.0), whereas ZS1 showed the smallest value over the entire frequency region (1.2-0.8). Several peaks could be observed at a higher frequency region for the ZS-1, ZS-2 and ZS-3 products. Generally, these peaks could be assigned to the dipolar polarization effect. ${ }^{31,32}$ The $\varepsilon^{\prime \prime}$ value cannot fully stand for the attenuation ability. If one absorber has a smaller $\varepsilon^{\prime}$ value, the larger $\varepsilon^{\prime \prime}$ value does not contribute to the final dielectric loss ability. Therefore, the effective attenuation ability generally can be calculated based on the following equation: ${ }^{33,34}$

$$
\alpha=\frac{\sqrt{2} \pi f}{c} \times \sqrt{\left(\mu^{\prime \prime} \varepsilon^{\prime \prime}-\mu^{\prime} \varepsilon^{\prime}\right)+\sqrt{\left(\mu^{\prime \prime} \varepsilon^{\prime \prime}-\mu^{\prime} \varepsilon^{\prime}\right)^{2}+\left(\mu^{\prime} \varepsilon^{\prime \prime}+\mu^{\prime \prime} \varepsilon^{\prime}\right)^{2}}}
$$

where $\alpha$ is the effective attenuation constant. A bigger $\alpha$ value generally indicates stronger effective attenuation ability. Among
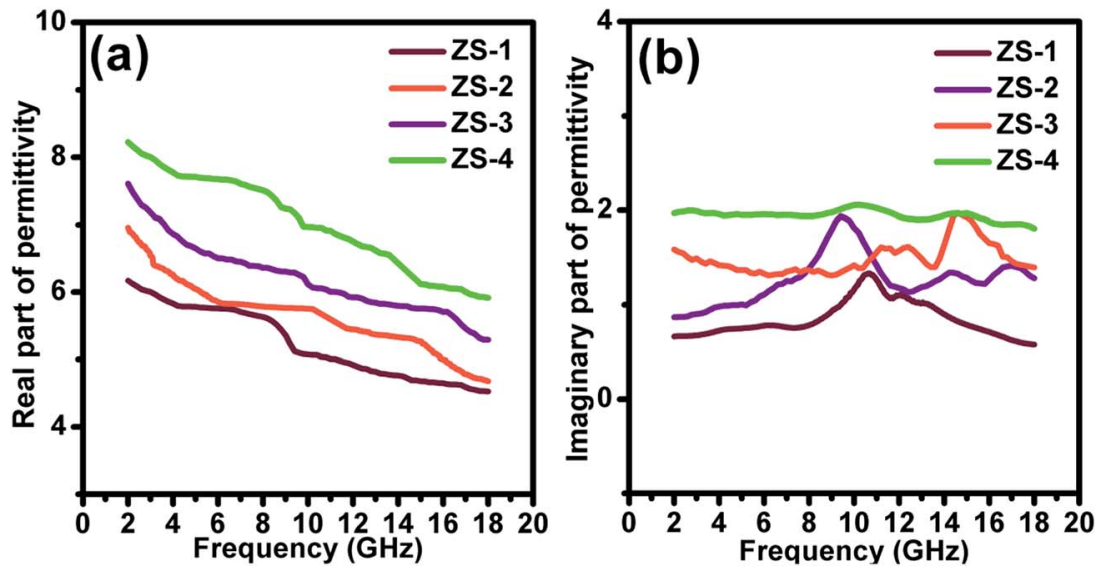

Fig. 5 Real (a) and imaginary (b) part of permittivity ZnS samples. 


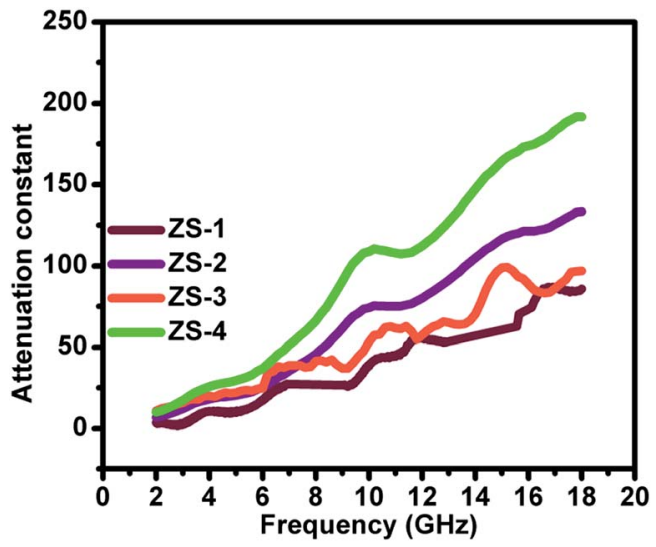

Fig. 6 Attenuation constant of the ZnS samples.

these samples, ZS-4 presented the largest $\alpha$ value, whereas ZS-1 showed the smallest, as indicated in Fig. 6. For the electromagnetic absorption properties, the ZS-1 sample was better than ZS-2, which could be explained by the improved impedance matching behavior (Fig. 7).

The dielectric loss is composed mainly of the conductive and polarization forms. Generally, conductive loss occurs in a highly conductive material, which should be ruled out for these $\mathrm{ZnS}$ materials. ${ }^{35}$ Considering the polarization effect, it generally involves the relaxation process, which can be expressed by the Cole-Cole semicircle. The relative complex permittivity can be described by the following equation: ${ }^{36,37}$

$$
\varepsilon_{\mathrm{r}}=\varepsilon_{\infty}+\frac{\varepsilon_{\mathrm{s}}-\varepsilon_{\infty}}{1+\mathrm{j} 2 \pi f \tau}=\varepsilon^{\prime}-\mathrm{j} \varepsilon^{\prime \prime}
$$

where $\varepsilon_{\mathrm{s}}, \varepsilon_{\infty}$, and $\tau$ are static permittivity, relative dielectric permittivity at high-frequency limit, and polarization relaxation time, respectively. Therefore, $\varepsilon^{\prime}$ and $\varepsilon^{\prime \prime}$ can be calculated using the following equations.

$$
\begin{gathered}
\varepsilon^{\prime}=\varepsilon_{\infty}+\frac{\varepsilon_{\mathrm{s}}-\varepsilon_{\infty}}{1+(2 \pi f)^{2} \tau^{2}} \\
\varepsilon^{\prime \prime}=\frac{2 \pi f \tau\left(\varepsilon_{\mathrm{s}}-\varepsilon_{\infty}\right)}{1+(2 \pi f)^{2} \tau^{2}}
\end{gathered}
$$

Based on eqn (7) and (8), the $\varepsilon^{\prime}-\varepsilon^{\prime \prime}$ can be expressed as

$$
\left(\varepsilon^{\prime}-\varepsilon_{\infty}\right)^{2}+\left(\varepsilon^{\prime \prime}\right)^{2}=\left(\varepsilon_{\mathrm{s}}-\varepsilon_{\infty}\right)^{2}
$$

Therefore, a plot of $\varepsilon^{\prime}-\varepsilon^{\prime \prime}$ should be a semicircle, which is generally called the Cole-Cole semicircle. Each Cole-Cole semicircle indicates one Debye relaxation process. The Debye relaxation process is related to the polarization forms, such as an electron, atomic, dipolar as well interface polarization. On the other hand, these samples do not present the Cole-Cole semicircle, indicating a weak polarization effect. This result is not consistent with the $\varepsilon^{\prime \prime}$ curve, as mentioned above. In other words, dipolar polarization is not stronger, and hence the ColeCole curve could be reflected.
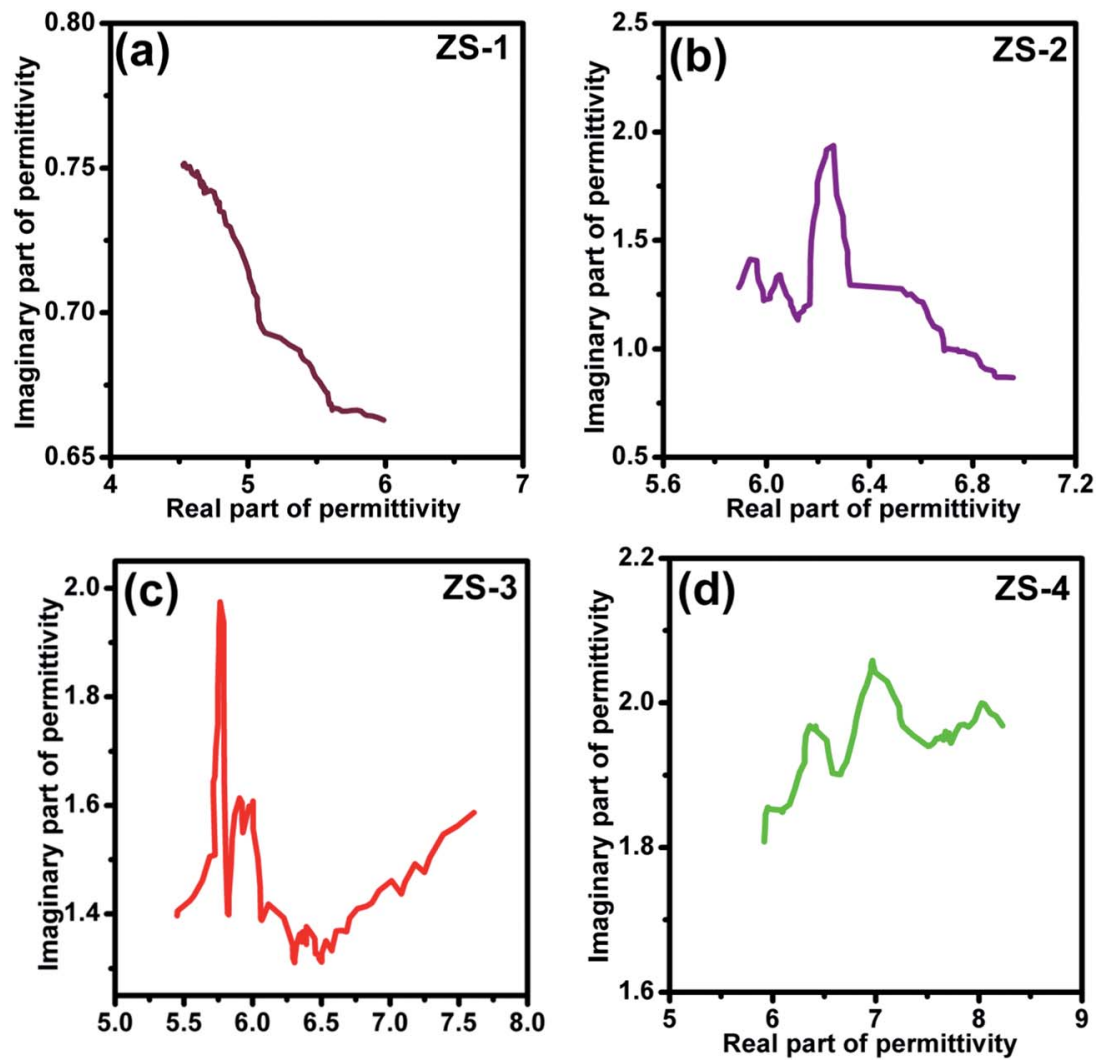

Fig. 7 Cole-Cole curves of the ZnS samples. 


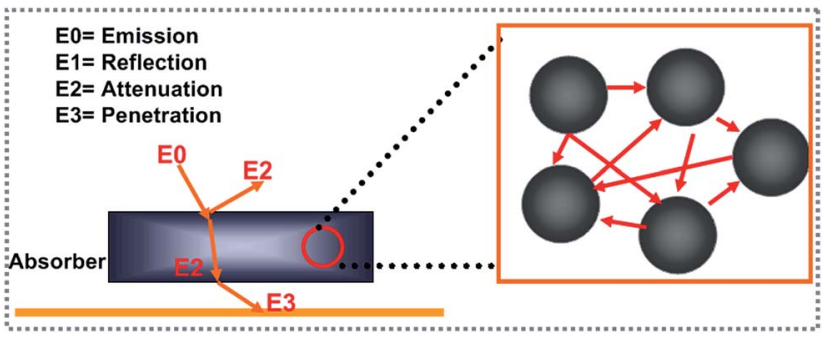

Fig. 8 Illustration of the scattering effect mechanism.

The electromagnetic wave scattering effect plays an important role in the attenuation of an electromagnetic wave. The detailed attenuation mechanism can be understood easily from Fig. 8. Generally, the incident electromagnetic wave (E0) can be divided into the following parts. One part of the electromagnetic wave will reflect directly from the absorber interface (E1). Subsequently, the entered electromagnetic wave can be attenuated (E2) or transmitted (E3) to the absorber. Commonly, a stronger scattering intensity results in a decrease in E3. According to the literature, a larger sized (generally larger than a micron) polyhedron structure as well as a rough surface influences the scattering intensity. ${ }^{38}$ In this study, the ZS-4 sample with the roughest surface showed the best electromagnetic absorption performance, which may be caused by the stronger scattering effect.

\section{Conclusion}

Through a simple hydrothermal process, rough spherical ZnS was achieved. Interestingly, the surface of $\mathrm{ZnS}$ sphere could be roughened by adding PVP as a surfactant. An analysis of the electromagnetic absorption properties showed that spherical $\mathrm{ZnS}$ with the roughest surface presented the stronger dielectric loss ability and electromagnetic absorption properties. In detail, the qualified absorption frequency of the optimal sample at $2.0 \mathrm{~mm}$ was up to $4.2 \mathrm{GHz}$. At the same time, the reflection loss was also less than $-30 \mathrm{~dB}$. A study of the attenuation mechanism suggested that these results were due to an electromagnetic scattering effect.

\section{Acknowledgements}

This study was supported financially by the Special Scientific Research Funds for Central Non-profit Institutes, Heilongjiang River Fishery Research Institute (HSY201402) and the Special Scientific Research Funds for Central Non-profit Institutes, Chinese Academy of Fishery Sciences (2016HY-ZD1205).

\section{References}

1 Y. Zhang, Y. Huang, T. F. Zhang, H. C. Chang, P. S. Xiao, H. H. Chen, Z. Y. Huang and Y. S. Chen, Adv. Mater., 2015, 27, 2049-2053.

2 X. F. Zhang, Y. X. Li, R. G. Liu, Y. Rao, H. W. Rong and G. W. Qin, ACS Appl. Mater. Interfaces, 2016, 8, 3494-3498.
3 H. L. Lv, H. Q. Zhang and G. B. Ji, Part. Part. Syst. Charact., 2016, 33, 656-663.

4 L. Saini, Y. Janu, M. K. Patra, R. K. Jani, G. K. Gupta and S. R. Vadera, J. Am. Ceram. Soc., 2016, 99, 3002-3007.

5 M. Zhou, F. Lu, B. T. Liu, J. Yang and X. H. Zeng, J. Phys. D: Appl. Phys., 2015, 48, 495303-495311.

6 H. L. Lv, G. B. Ji, W. Liu, H. Q. Zhang and Y. W. Du, J. Mater. Chem. C, 2015, 3, 10232-10241.

7 D. Moitra, M. Chandel, B. K. Ghosh, R. Jani, M. K. Patra, S. Vaderab and N. N. Ghosh, RSC. Adv., 2016, 6, 76759-76772.

8 T. Liu, Y. Pang, X. B. Xie, W. Qi, Y. Wu, S. Kobayashi, J. Zheng and X. G. Li, J. Alloys Compd., 2016, 667, 287-296.

9 Y. Z. Wan, T. Cui, J. Xiao, G. Y. Xiong, R. S. Guo and H. L. Luo, J. Alloys Compd., 2016, 687, 334-341.

10 Y. Li, J. Zhang, Z. W. Liu, M. M. Liu, H. J. Lin and R. C. Che, J. Mater. Chem. C, 2014, 2, 5216-5222.

11 R. L. Ji, C. B. Cao, Z. Chen, H. Z. Zhai and J. Bai, J. Mater. Chem. C, 2014, 2, 5944-5953.

12 H. J. Wu, G. L. Wu, Y. Y. Ren, L. Yang, L. D. Wang and X. H. Li, J. Mater. Chem. C, 2015, 3, 7677-7690.

13 J. C. Park and Y. S. Nam, J. Colloid Interface Sci., 2015, 460, 177-180.

14 X. J. Xu, L. F. Hu, N. Gao, S. X. Liu, S. Wageh, A. Ghamdi, A. Alshahire and X. S. Feng, Adv. Funct. Mater., 2015, 21, 445-454.

15 X. Z. Lin, A. Ennaoui, S. Levcenko, T. Dittrich, J. Kavalakkatt and S. Kretzschmar, Appl. Phys. Lett., 2015, 106, 013903013907.

16 H. L. Lv, H. Q. Zhang, B. S. Zhang, G. B. Ji, Y. He and Q. Lin, J. Mater. Chem. C, 2016, 4, 5476-5482.

17 M. Q. Ning, M. M. Lu, J. B. Li, Z. Chen, Y. K. Dou, C. Z. Wang, F. Rehman, M. S. Cao and H. B. Jin, Nanoscale, 2015, 7, 15734-15740.

18 X. G. Liu, C. Feng, N. N. Bi, Y. P. Sun, J. C. Fan, Y. H. Lv, C. G. Jin, Y. R. Wang and C. T. Li, Ceram. Int., 2014, 40, 9917-9922.

19 Y. H. Zhang, N. Zhang, Z. R. Tang and Y. J. Xu, ACS Nano, 2012, 6, 9777-9789.

20 J. Y. Park, S. J. Park, J. H. Lee, C. H. Hwang, K. J. Hwang, S. H. Jin, D. Y. Choi, S. D. Yoon and I. H. Lee, Mater. Lett., 2014, 121, 97-100.

21 H. L. Lv, G. B. Ji, X. H. Liang, H. Q. Zhang and Y. W. Du, J. Mater. Chem. C, 2015, 3, 5056-5064.

22 M. Zhou, X. Zhang, J. M. Wei, S. L. Zhao, L. Wang and B. X. Feng, J. Phys. Chem. C, 2011, 115, 1398-1402.

23 B. Zhao, G. Shao, B. B. Fan, W. Y. Zhao, Y. J. Xie and R. Zhang, RSC Adv., 2014, 4, 61219-61225.

24 S. He, G. S. Wang, C. Lu, X. Luo, B. Wen, L. Guo and M. S. Cao, ChemPlusChem, 2013, 78, 250-258.

25 T. Y. Huang, M. He, Y. M. Zhou, S. W. Li, B. B. Ding, W. L. Pan, S. Huang and Y. Tong, RSC Adv., 2016, 6, 100392-100400.

26 X. Ding, Y. Huang, S. P. Li, N. Zhang and J. G. Wang, Composites, Part A, 2016, 90, 424-432.

27 D. Z. Chen, H. Y. Quan, G. S. Wang and L. Guo, ChemPlusChem, 2013, 78, 843-851. 
28 X. H. Guan, P. Gu and G. S. Wang, RSC Adv., 2014, 4, 1557915585.

29 H. L. Lv, Y. H. Guo, Y. Zhao, H. Q. Zhao, B. S. Zhang, G. B. Ji and Z. C. J. Xu, Carbon, 2016, 110, 130-137.

30 M. Fu, Q. Z. Jiao, Y. Zhao and H. S. Li, J. Mater. Chem. A, 2014, 2, 735-744.

31 H. L. Lv, H. Q. Zhang, G. B. Ji and Z. C. Xu, ACS Appl. Mater. Interfaces, 2016, 8, 6529-6538.

32 M. Zhou, F. Lu, B. Chen, X. Y. Zhu, X. S. Shen, W. W. Xia, H. He and X. H. Zeng, Mater. Lett., 2015, 159, 498-501.

33 G. Wang, X. Peng, L. Yu, G. Wan, S. Lin and Y. Qin, J. Mater. Chem. A, 2015, 3, 2734-2740.
34 Y. Liu, X. X. Liu, R. Liu, W. Wu and X. J. Wang, RSC Adv., 2015, 5, 8713-8720.

35 Y. P. Duan, Z. Liu, H. Jing, Y. H. Zhang and S. Q. Li, J. Mater. Chem. A, 2012, 22, 18291-18299.

36 G. P. Wan, L. Yu, X. G. Peng, G. Z. Wang, X. Q. Huang, H. N. Zhao and Y. Qin, RSC Adv., 2015, 5, 77443-77448.

37 M. Zhou, F. Lu, T. Y. Lv, X. Yang, W. W. Xia, X. S. Shen, H. He and X. H. Zeng, J. Phys. D: Appl. Phys., 2014, 48, 215305215311.

38 H. L. Lv, H. Q. Zhang, J. Zhao, G. B. Ji and Y. W. Du, Nano Res., 2016, 6, 1813-1822. 